\title{
Projeto Pipoca Clássica: o uso do cinema como ferramenta para discussão e ensino da Antiguidade Clássica
}

"Pipoca Clássica" Project: The use of films as a method to discuss and teach Classical Antiquity

\author{
Carolina Kesser Barcellos Dias* \\ Dayanne Dockhorn Seger** \\ Milena Rosa Araújo Ogawa ${ }^{* * *}$
}

\section{Resumo}

A comunicação entre pesquisadores e público geral é tema de debate crescente em diversas áreas, visando cobrir o grande vazio existente entre o que produzimos para "nossos pares" e o restante do público. Nesse enfrentamento, surge a necessidade de explicar o porquê de estudar sociedades tão cronologicamente distantes de nós, (re)significando-as com questões que podem ser problematizadas no presente. Entendemos que as produções cinematográficas podem servir como veículo didático-pedagógico, pois proporcionam a tridimensionalização de

\begin{abstract}
The communication between researchers and the public is a topic of discussion that has increased in several fields during the last years, addressing the gap between what we produce for "our peers" and the rest of the public. In this confrontation, it becomes important to clarify why we study ancient societies, (re)signifying them by topics that can be problematized today. Films can become a didactic-pedagogical instrument, since they provide a three-dimensional frame for a historical period that is often treated as a minor subject in the
\end{abstract}

\footnotetext{
* Doutora em Arqueologia pelo Museu de Arqueologia e Etnologia da Universidade de São Paulo (MAE-USP). Coordenadora e pesquisadora-associada do Laboratório de Estudos sobre a Cerâmica Antiga (Leca) da Universidade Federal de Pelotas (UFPel), professora permanente no Programa de Pós-Graduação em História da Universidade Federal de Pelotas (PPGH-UFPel), pós-doutoranda e bolsista Capes no mesmo programa. Pelotas, RS, Brasil. carol.kesser@gmail.com

** Bacharel em Antropologia Social e Cultural pela Universidade Federal de Pelotas (UFPel). Pesquisadora e colaboradora no Laboratório de Estudos sobre a Cerâmica Antiga (Leca) da Universidade Federal de Pelotas (UFPel). Pelotas, RS, Brasil. dayannedockhorn@gmail.com

*** Mestre em História pela Universidade Federal de Pelotas (UFPel), Especialista em Direitos Humanos e Cidadania pela Universidade Federal do Pampa e pesquisadora do Laboratório de Estudos sobre a Cerâmica Antiga (Leca) da Universidade Federal de Pelotas (UFPel). Pelotas, RS, Brasil.ogawa_milena@hotmail.com.br
} 
um período histórico temporal que por muitas vezes é trabalhado em sala de aula de forma pouco abrangente. Nessa perspectiva, este artigo visa apresentar e discutir experiências no âmbito do projeto de extensão Pipoca Clássica, que buscou um diálogo multidisciplinar e extramuros mediante exibição e posterior discussão de filmes inspirados em temas da antiguidade para o público infanto-juvenil. Palavras-chave: ensino de História; cinema; História Antiga. classroom. Based on this background, the present study aims to introduce and examine the activities within the "Pipoca Clássica” Project, whose intention was to deliver a multidisciplinary dialogue through the exhibition and the debate of movies inspired by Ancient History topics.

Keywords: History teaching; films; Ancient History.

Quando estudamos História Antiga no Brasil, deparamos com uma lacuna no que concerne à divulgação científica da nossa área, atualmente pouco presente nos meios de comunicação (jornais, revistas, televisão e mídias sociais). Tendo em vista que o conhecimento e as representações do passado que criamos, enquanto pesquisadores, dizem respeito às tradições e heranças de pelo menos parte da sociedade moderna ocidental, é pertinente questionar por que os dados, informações e interpretações que levantamos não circulam fora dos meios acadêmicos.

A comunicação entre pesquisadores e público geral é tema de debate crescente em diversas áreas do conhecimento. Como pesquisadores, estamos cada vez mais cientes de que é preciso desenvolver e considerar novos métodos de divulgação científica. Porém, na maioria das vezes, essas constatações não encontram resultados no sentido da maior e melhor difusão dos temas que estão sendo pesquisados no âmbito da universidade, nem mesmo no que se refere aos livros didáticos da educação básica (Silva, 2014). Muitas vezes, essa ineficácia em alcançar o público se deve à dificuldade ou inexistência de comunicação no momento do desenvolvimento de projetos de pesquisa e também durante sua execução. Quando contemplamos a comunicação científica atual - feita pela publicação de artigos, seminários, palestras e eventos dentro da universidade, entre outros -, percebemos como sua linguagem é voltada inteiramente aos especialistas, sendo bastante diferente daquela utilizada pelos meios de comunicação ou de divulgação científica (Dias et al., 2013). Nesse contexto, para difundir as pesquisas e ampliar seu alcance extramuros é necessário ajustar o tom do discurso e buscar outras maneiras de atuação, um 
esforço muitas vezes não realizado nem contemplado pelos pesquisadores. Quando proposto, esse diálogo fica a cargo dos projetos de extensão e de formação continuada para professores do ensino básico que, além de estimularem a reflexão sobre o próprio fazer científico, também promovem a interação e a compreensão da ciência que está sendo trabalhada, incentivando a disseminação de informações científicas geradas pelos pesquisadores para a sociedade.

No caso da História, é contínuo o enfrentamento dos pesquisadores com o público, principalmente o infanto-juvenil, durante o Ensino Fundamental e Médio, mas não se restringindo a ele. Nesses contextos, surge a necessidade de explicar, muito pontualmente, o porquê de estudar períodos, culturas e sociedades tão cronologicamente distantes de nós, (re)significando-os com questões que podem ser problematizadas no presente. O caso da História Antiga é particularmente mais difícil: mesmo quando abordada nos planos de aula de História, por causa de seu caráter obrigatório, ela ainda fica bastante marginalizada e fragmentária diante do restante do conteúdo. ${ }^{1}$

Ao lidar com sociedades antigas e períodos cronologicamente muito distantes do nosso, é imprescindível explicitar o modo como o passado, seus discursos e representações apresentam consequências, continuidades e rupturas em relação às sociedades do presente. Nesse sentido, entendemos que as produções cinematográficas podem servir como veículo didático-pedagógico importante para a transposição didática (Van Dyke, 2006; Silva; Figueiredo, 2012), pois elas proporcionam a tridimensionalização de um período histórico-temporal que por muitas vezes é trabalhado em sala de aula de forma pouco abrangente e nada dinâmica. Desse modo, entendemos que o cinema pode auxiliar e aprimorar a comunicação e o engajamento dos estudantes do ensino básico com os temas da Antiguidade, utilizando-os como ponto de partida para as questões discutidas em aula.

Vale ressaltar que é perceptível no meio acadêmico a rejeição pelos filmes baseados em fatos ou períodos históricos (Zapatero; Castaño, 2008; McGeough, 2006; Rosenstone, 1995), uma vez que são sempre considerados como a-históricos, e muitas vezes debatidos com base em seus anacronismos e falhas de representação. Contudo, nossa abordagem se opõe a essa posição: propomos tratar os filmes de modo a discutir suas percepções, representações e apropriações das culturas antigas, pois entendemos que o índice de reprodução das representações cinematográficas com temas versando sobre Arqueologia 
Clássica e História Antiga excede em muito o índice no qual o público experimenta essas disciplinas na realidade do seu trabalho dentro das universidades (Holtorf, 2007).

Temos o comprometimento social de fornecer significados, pertencimentos e espaços de inclusão para diversos e inúmeros grupos, no tempo e no espaço. Ao mesmo tempo, estamos próximos de símbolos, resquícios culturais e materiais, museus históricos e arqueológicos, séries, filmes e documentários que retratam a Antiguidade com base em diferentes interpretações, pontos de vista e narrativas. Todos esses servem para demonstrar que há interesse na experiência do passado, não importa quão longínquo esteja, e que ele tem algo a ensinar, a mostrar, algo que diz respeito a nós e à nossa situação atual. Entretanto, questionamo-nos: estamos utilizando esses recursos com tais objetivos?

O propósito de estudar as representações da Antiguidade no cinema geralmente vem ao encontro dos meios de divulgação científica, visto que busca compreender a percepção do público a respeito das sociedades antigas e, desse modo, interagir melhor com as audiências populares (McGeough, 2006). Os filmes oferecem o passado como experiência; apresentam acontecimentos fechados dentro de uma sociedade estruturada e representativa, composta por um número limitado de atores sociais. Estruturas, relações e papéis sociais que se criam são muito parecidos com os nossos, independentemente da mudança de valores e instituições e da cronologia recuada. Promove-se, assim, a empatia do público com o passado, que não se preocupa com a sustentação científica dos fatos mais do que pretende "vivenciar" uma boa narrativa.

Talvez mais do que qualquer outra mídia, o cinema pode servir como instrumento para conectar pesquisadores e público, favorecendo o diálogo e o engajamento da sociedade com os assuntos levantados na academia (Van Dyke, 2006). Ou seja, ao conversar sobre os filmes produzidos sobre História Antiga, já estaremos discutindo suas percepções, representações e apropriações dessas culturas, levantando questões próprias que entrelaçam História, Arqueologia e cinema.

À luz dessas reflexões, o presente artigo apresenta e pretende debater as experiências do projeto de extensão Pipoca Clássica, que desde 2014 desenvolve ações para difundir temas da Antiguidade, criando um debate interdisciplinar dentro na universidade e estabelecendo ligações com o público geral. Com base nessas experiências, podemos afirmar que o principal resultado obtido 
com o projeto foi a aproximação do cinema e de outras áreas do conhecimento às questões discutidas no âmbito da Arqueologia e da História, bem como seu uso como ferramenta didático-pedagógica durante oficinas ministradas com o público infanto-juvenil.

\section{O CINEMA COMO FERRAMENTA PARA o Ensino da Antiguidade Clássica}

É comum historiadores e arqueólogos evitarem discutir filmes, séries e documentários de caráter histórico, ou seja, produções que tratam de assuntos muitas vezes "apropriados” por esses pesquisadores. De acordo com Robert Rosenstone (1995), isso acontece porque nós, os investigadores, julgamos os filmes da mesma maneira que julgaríamos uma obra científica, com enorme rigor acadêmico. Nessa linha, somos induzidos, na maioria das vezes, a rotulá-los como incorretos, falsos e imprecisos, distanciando-os ao máximo das pesquisas científicas "sérias". Além disso, somos levados a afirmar, com bastante certeza, que os filmes distorcem o passado, que romantizam personalidades, eventos e fatos e que, por fim, transmitem um conhecimento equivocado. No entanto, como bem apontou Rosenstone, para além dessas razões, os filmes não agradam os pesquisadores porque estão fora do nosso controle, porque nos mostram que o "nosso objeto de estudo" não é, de fato, nosso. Percebemos, por meio deles, que o passado está aberto a interpretações e representações, e que a História e a Arqueologia não são as únicas que se interessam por ele.

Como o conhecemos hoje, o cinema acessa públicos incrivelmente heterogêneos e pode despertar neles o interesse por temas pouco tratados em outros meios. Os filmes concedem uma experiência ao espectador, criam uma verdadeira jornada ao passado, com a qual nossas pesquisas, literalmente feitas de papel e tinta, não conseguem competir. A facilidade com que o cinema entrega o passado ao público o tornou, para muitos, a primeira fonte de conhecimento sobre o passado distante, inclusive para os pesquisadores. Conforme comentam Carlan et al. (2015, p.2), “o cinema foi o grande responsável por potencializar a imaginação sobre quase tudo, inclusive a Antiguidade. E isso tem sido fundamental para que os próprios estudiosos do passado formem suas ideias a respeito da História”. 
Ademais, o cinema sempre esteve bastante interessado em História e Arqueologia, graças ao grande apelo e curiosidade que o passado, veiculado de modo misterioso, e as civilizações antigas, entendidas muitas vezes como "exóticas", despertam no público. No entanto, esse interesse não foi recíproco, e os temas da divulgação científica e do uso dos filmes como ferramenta didática foram vistos de forma pejorativa na academia (Silva, 2014). Atualmente, é possível ver esse pensamento em transformação, estando cada vez mais em prática a análise, por parte dos pesquisadores, de filmes que tratam de temas históricos e da relação entre cinema e História (Zapatero; Castaño, 2008; Silva; Figueiredo, 2012; Carlan et al., 2015). A potencialidade de tornar o passado mais acessível por meio dos filmes despertou um diálogo profícuo nas últimas décadas, criando até mesmo revistas acadêmicas, livros, eventos e dossiês dedicados ao tema. Nessa linha, os filmes também ganharam espaço nas salas de aula como modo de dinamizar um conteúdo que, dentro da metodologia de ensino atual, ainda parece muito distante e carece de sentido.

O ensino da História Antiga no país, ainda que presente no currículo da educação básica, geralmente fica marginalizado em relação à História do Brasil, já que existem descontinuidades e uma grande dificuldade de relacionar, na sala de aula, as sociedades antigas e a sociedade brasileira atual. Desse modo, tido como elitista por muitos professores e pesquisadores, o estudo da História Antiga deve transpor uma barreira a mais no ensino: deve justificar o porquê da sua existência. O material didático tampouco parece ajudar: completamente dissociado das pesquisas que ocorrem nas universidades brasileiras (Silva, 2014), ele tende a ensinar uma versão fragmentária das sociedades antigas, escolhendo vieses e determinados períodos pelos quais analisá-las, como se estivessem congeladas no tempo. O Egito Antigo, por exemplo, é visto principalmente em seu aspecto funerário: conforme Thais Silva, "pirâmides, múmias, a monumentalidade das construções e a sobrevivência dos egípcios numa região quente e desértica constituem ainda grande parte dos temas elencados para se falar de Egito" (Silva, 2014, p.281). Esse contexto suscita duas demandas que nós, pesquisadores da Antiguidade, devemos abraçar: a primeira, demonstrar o porquê de estudar as sociedades antigas no presente e no Brasil, seja na sala de aula, seja na universidade; e a segunda, comunicar-se com o público não especialista, realizando a divulgação científica por meio de uma abordagem didática e inclusiva. 
Nessa perspectiva, entendemos os filmes como meios dinâmicos e interativos, que proporcionam ao público acesso a diversos conteúdos e problemáticas atuais. Experimentar o passado - e, mais especificamente, o passado que denominamos História Antiga - por intermédio de histórias contadas pelo cinema é uma das formas mais eficientes de que dispomos atualmente para dar sentido a essas culturas, contextualizando também a nossa posição enquanto pesquisadores da Antiguidade. É claro que, para suscitar o conhecimento histórico, a mediação dos professores ou pesquisadores é fundamental, pois eles podem levantar uma perspectiva crítica em relação aos filmes, despertando as conexões com o presente e com a sociedade que produziu essas representações, ao mesmo tempo permitindo a aproximação de um passado distante no tempo e no espaço.

A visão de que os filmes conformam um documento histórico parte de Ferro (1992), que defende serem eles imagens tanto da sociedade que retratam quanto da sociedade que os produz. Espera-se, desse modo, que a análise das produções cinematográficas não se baseie meramente na narrativa ficcional, que elas sejam vistas também como informação sobre a sociedade e a época que as produziram. Dessa forma, quando abordamos os filmes como ferramenta didático-pedagógica para o público infanto-juvenil, é importante pesarmos algumas questões relativas ao modo como o passado é representado no cinema, que pode estar diretamente ligado a questões atuais. Devemos, também, esclarecer para o público que os filmes não têm compromisso com determinada sequência cronológica ou com a "verdade", mas que têm o poder de criar e manipular narrativas com base na liberdade e no fazer artístico. Portanto, é importante esclarecer que cabe a nós, mediadores, inserir o filme e suas representações na História.

\section{O projeto Pipoca Clássica}

O Pipoca Clássica foi criado em 2014 como um projeto de extensão de caráter multidisciplinar, desenvolvido pelos integrantes do Laboratório de Estudos sobre a Cerâmica Antiga (Leca-UFPel) ${ }^{2}$ e com a colaboração ${ }^{3}$ de docentes, pesquisadores e discentes da Graduação e do Programa de Pós-Graduação em História da Universidade Federal de Pelotas (UFPel) e de outras universidades do país, especializados nas áreas de Arqueologia, História da Arte, Letras, 
Filosofia e Cinema. Ao abordar sistematicamente produções cinematográficas inspiradas em temas da História Antiga, nosso intuito foi discutir questões relativas à recepção da Antiguidade e ao uso da historiografia antiga e moderna.

As sessões do Pipoca Clássica são organizadas em ciclos temáticos, que ajudam na escolha das produções e dos tópicos de discussão e contam com mediadores que norteiam a discussão após a exibição dos filmes. Cada ciclo exibe cerca de três filmes em intervalos regulares.

Após 2 anos do início do projeto, sentimos não estar alcançando o público extramuros com as sessões e os ciclos acontecendo dentro da universidade. Preocupados em fomentar a discussão sobre as percepções da Antiguidade com o público não especialista, desenvolvemos uma extensão do projeto, chamado Pipoquinha Clássica.

Com o Pipoquinha, buscamos atuar em escolas públicas e privadas e espaços de ensino não formal com o intuito de acessar o público infanto-juvenil. Para isso, foi necessário reformular nossa metodologia, fazendo que o uso do cinema se tornasse um meio didático para levantar questões referentes à História Antiga, à Arqueologia, ao fazer histórico e científico e ao cinema. Propusemos a exibição de animações, desenhos, séries de televisão e longas-metragens que desenvolvessem a temática da Antiguidade sob diferentes óticas e, acompanhando cada sessão, oferecemos atividades e/ou oficinas relativas aos conteúdos dos filmes, em consonância com as necessidades da disciplina ministrada, ou com os interesses do próprio grupo infanto-juvenil, obedecendo às metodologias didáticas e de ensino nas áreas da História.

Nossa primeira experiência se deu em ambiente de ensino não formal, no espaço de uma organização não governamental (ONG) localizada na cidade de Rio Grande (RS, Brasil) em 2015. A ONG Colmeia atende, no turno inverso ao das aulas do ensino básico, estudantes de todas as idades, contando com professoras e um espaço para aulas de reforço e atividades diversas. Nessa primeira experiência, trabalhamos com estudantes entre 3 e 13 anos de idade. No primeiro encontro, exibimos no espaço da ONG um episódio da série animada Hércules ${ }^{4}$ (1998), que propôs um primeiro contato dos estudantes com o tema da mitologia grega e com as discussões que se seguiriam. Antes e após a exibição do episódio, delineamos um pensamento reflexivo entre o que era visto no desenho e a nossa realidade: quem éramos, o que fazíamos, por 
que estávamos ali e por que falávamos sobre Hércules e Grécia antiga. Nesse sentido, os estudantes também foram questionados sobre seu nível de conhecimento e interesse no assunto.

Para a segunda atividade com a ONG Colmeia, os estudantes viajaram até Pelotas (RS, Brasil) a nosso convite. Nesse encontro, o grupo já era maior e composto por crianças e jovens entre 7 e 18 anos. A atividade que preparamos foi, portanto, um pouco diferenciada. No primeiro momento, realizamos um passeio a pé pelo centro da cidade, destacando as referências da arquitetura clássica vistas no episódio de Hércules. Isso foi possível porque muitos prédios do centro histórico de Pelotas adotam o estilo neoclássico. Em seguida, visitamos o Mercado Público da cidade, que abriga uma escultura de Hermes, divindade grega assimilada pelos romanos como Mercúrio. Essa escultura é feita em metal, mede pouco mais de 2 metros de altura e tem como inspiração a obra do escultor Giambologna (1529-1608), atualmente exposta no Museu Nacional de Bargello (Florença, Itália).

Sabe-se que a escultura ocupou o alto da torre do Mercado Público durante parte do século XX, tendo sido possivelmente derrubada por um vendaval. A escultura da divindade grega relacionada ao comércio no alto da torre do Mercado - que hoje recebe visitas em uma sala especial do prédio - serviu como estudo para pesquisa sobre memória social e patrimônio cultural (Torino, 2015) e nos auxiliou, na primeira experiência do Pipoquinha, a materializar as discussões e relações entre presente e passado.

O passeio terminou no Museu do Doce da Universidade Federal de Pelotas (Figura 1), onde tudo que havíamos visto foi sistematizado e reforçado com a exibição de dois filmes e sua posterior discussão. A diferença significativa de faixa etária entre os participantes nos motivou a dividir o grupo em dois e trabalhar longas-metragens distintos: Hércules (Brett Ratner, 2014) e Hércules (Ron Clements e John Musker, 1997). O primeiro foi exibido para o público de 14 a 18 anos, e o último, para o público de 7 a 13 anos. A metodologia com que conduzimos as atividades após os filmes também foi diferenciada. Contudo, buscamos enfatizar essas problemáticas em ambos os grupos: contextualização espacial da Grécia antiga, relacionando-a ao Brasil por meio de mapas e do globo; o conceito de mitologia e mitologia grega, destacando deuses, semideuses e animais mitológicos presentes nos filmes; a arquitetura e as referências gregas que podemos notar em nossas próprias cidades ainda 
hoje, fazendo uma relação entre passado e presente; por fim, uma reflexão sobre o fazer histórico e arqueológico, demonstrando o porquê de estudar a Grécia desde o Brasil, e as possibilidades que os jovens têm, na forma de cursos superiores, para adentrar esse campo.

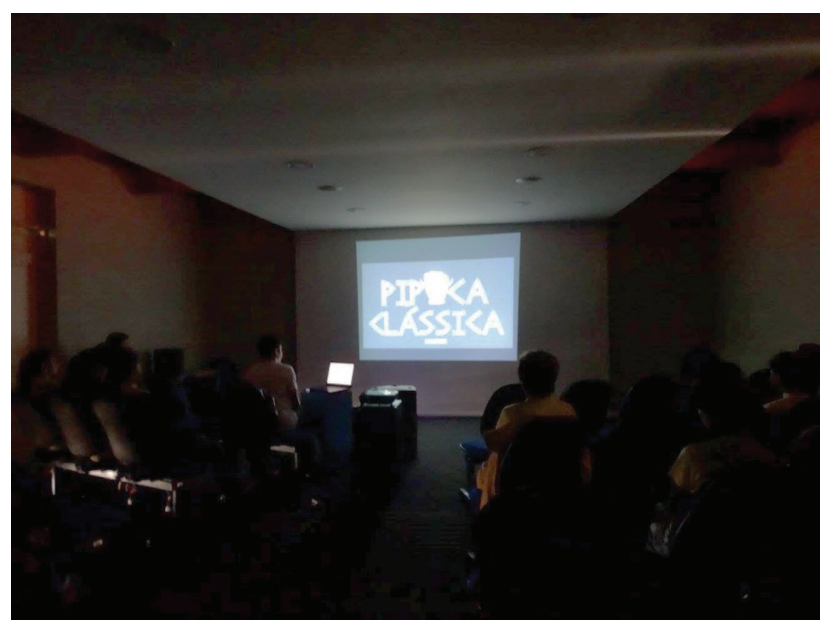

Figura 1 - Sessão de cinema com jovens e crianças da ONG Colmeia, no Museu do Doce, em Pelotas. Fonte: Acervo Leca-UFPel.

A resposta dos jovens à metodologia aplicada foi bastante positiva, e como forma de dar continuidade a essa experiência, preparamos um material composto por atividades didáticas sobre mitologia grega que as professoras da ONG passariam a utilizar nas suas aulas de reforço. O segundo evento realizado pelo Pipoquinha Clássica também ocorreu em ambiente de ensino não formal, a Companhia de Dança Afro Daniel Amaro. Conformando quatro encontros e três sessões de cinema, é sobre ela que iremos nos deter no restante do artigo.

\section{A experiênCia do Pipoca Clássica na} Companhia de Dança Afro Daniel Amaro

Em 2016, o Pipoquinha Clássica desenvolveu um projeto multidisciplinar de Cinema, História e Arqueologia com os alunos da Companhia de Dança Afro Daniel Amaro, na Vila Castilho, em Pelotas. Em 12 de maio, promoveu-se 
uma roda de conversa na qual o projeto foi apresentado e, assim, estabeleceu-se a ordem de sessões para discussão dos temas norteadores. As sessões foram ministradas nos dias 20 de maio, 7 e 18 de junho. Todas as atividades ocorreram na sede da Companhia de Dança e contaram com a presença do prof. Daniel Amaro, da Diretora Cultural da Companhia, Fernanda Ferreira do Amaral, e de jovens entre 8 e 18 anos, alunos da Companhia, que delinearam alguns tópicos de discussão para o projeto.

No primeiro encontro, buscamos estabelecer um diálogo com os jovens, investigando com quais atividades eles mais se identificavam dentro e fora do ambiente escolar. Quase em uníssono, afirmaram não ter um vínculo positivo com o ambiente da escola. A respeito da disciplina de História, apontaram que se baseava na metodologia de cópia dos livros didáticos e questionários semiestruturados. Em seguida, questionamos se eles sabiam do que se tratava a História Antiga. Os adolescentes, que ainda se mostravam desinteressados em nossos questionamentos, responderam com frases como "é tudo que é velho", "algo que passou há muito tempo".

Aprofundando o diálogo, procuramos saber quais filmes eles conheciam sobre esse assunto. Pelas respostas, percebemos que, das civilizações citadas, a egípcia era a que causava maior interesse e curiosidade. Essa repercussão pode estar relacionada a novelas e minisséries bíblicas produzidas pela rede de comunicações televisivas Record, da qual os alunos são espectadores.

Em seguida, diante do nosso questionamento sobre qual temática mais os interessava no âmbito do cinema e da Antiguidade, responderam que gostariam de ver mais películas que abordassem temáticas voltadas ao Egito e às mulheres - as alunas são maioria nessa Companhia. Também mencionaram que não se sentiam representados nos filmes: "Não vemos atores nem filmes com negros".

Com base nessa afirmação, questionamos se os negros eram representados nos conteúdos ministrados em sala de aula. Alguns responderam que sim, mas evidenciando que apenas em temas relacionados à escravidão no Brasil, o que nos fez refletir sobre as perspectivas pelas quais se constroem a imagem e os papéis sociais dos negros na sociedade brasileira. Mesmo com a Lei 10.639/03, de 9 de janeiro de 2003, que visava inserir o Ensino de História e Cultura Afro-brasileira e Africana no Ensino Fundamental e Médio em caráter obrigatório, numa tentativa de equiparar os sujeitos históricos problematizados em sala de 
aula e contribuir para que o aluno observe a diversidade cultural e reflita sobre as contribuições sócio-históricas e econômicas da comunidade afrodescendente, os temas ainda não são abordados de maneira constante ou consistente.

Nesse sentido, vale ressaltar que os professores que tiveram na graduação as disciplinas de História da África e História Indígena são apenas das turmas de 2010 em diante. É necessário repensar o modo e o período em que esses conteúdos estão sendo trabalhados em sala de aula e também qual o seu protagonismo nos cursos superiores de História. Segundo a Lei 9.394, de 20 de dezembro de 1996, tal temática pode ser debatida nas áreas de História, Literatura e Educação Artística (Art. $26 \mathrm{~A}, \$ 2^{\circ}$ ). Assim, cabe lembrar que a abordagem do ensino da cultura africana não recai apenas sobre os professores de História, sendo necessário construir um diálogo interdisciplinar.

A escolha para os temas dos próximos encontros foi marcada, portanto, pelas demandas dos próprios jovens. Nossa intenção, com os filmes, seria discutir a representação negra por intermédio da civilização egípcia, trazendo para debate questões que entrelaçavam História Antiga, Arqueologia e cinema, e que também poderiam ser trazidas ao presente, refletindo sobre nossa sociedade e identidade.

A primeira sessão do Pipoquinha discutiu o tema "História", sendo orientada pela discente do Programa de Pós-Graduação em História, Milena Rosa Araújo Ogawa. Projetou-se aos estudantes o "O Rei dos Assassinos” ( $8^{\circ}$ episódio da $3^{\text {a }}$ temporada) da série de televisão Xena, a Princesa Guerreira (Xena: Warrior Princess, 1995). A discussão centrou-se na figura de Cleópatra e em sua representação no cinema e na documentação histórica. Nesse episódio, verifica-se a única representação de uma Cleópatra negra, em contraposição às demais obras conhecidas cinematograficamente.

Por meio desse episódio, observamos como as películas logram transmitir memórias, sentimentos, significados, momentos e lugares que os livros didáticos, sozinhos, não conseguem. Foi possível mostrar a desmistificação dos negros enquanto seres castigados, escravizados e passivos da História. Houve, por parte das ministrantes, um discurso voltado à valoração da estrutura social e econômica e do "ideal" de beleza que os egípcios conseguiram construir, mostrando vínculos de ancestralidade e descendência e proporcionando uma discussão sobre identidade social. Verificamos que tal linguagem poderia ser um método profícuo para o ensino de forma dinâmica e interativa, levantando 
diversas questões relativas à compreensão histórica da Antiguidade. Questões como “Cleópatra era mesmo negra?” e “Aquela cena aconteceu mesmo?” permitiram que, após a exibição, abordássemos os tipos de fontes históricas disponíveis sobre o tema, deixando claro que os filmes poderiam, ou não, se basear nelas. Nesse sentido, ressaltamos que os diretores e roteiristas não têm compromisso com dados e fatos históricos ao retratar o passado, diferentemente de nós, arqueólogos e historiadores.

Na discussão, a personagem Cleópatra VII foi apresentada como uma mulher pertencente à linhagem greco-macedônica, uma dinastia caucasiana que teria dominado o Egito Antigo após a morte do conquistador Alexandre, o Grande (século IV a.C.). Contudo, Cleópatra VII é uma mulher do século I a.C., fruto de miscigenação pelos laços de casamento e interações culturais próprias. Nesse sentido, o debate centrado na questão "seria Cleópatra branca ou negra?" acaba se tornando uma disputa entre os que querem embranquecê-la e os que querem enegrecê-la, graças à representatividade e o impacto político que ela causou na Antiguidade e ainda causa hoje.

Outro debate proposto sobre Cleópatra VII ser branca ou negra desenvolveu-se observando o atrelamento da quantidade de melanina como influenciadora do conceito de belo na contemporaneidade. A rainha sempre foi vinculada à beleza e ao poder, considerada uma das mulheres mais representativas da história. Considerá-la como pertencente a um grupo a colocaria como símbolo político de idealização da figura feminina com poder (Balthazar, 2013). Porém, esses discursos acabam enfraquecidos se não problematizarem a mestiçagem e hibridização entre o helenismo e a cultura egípcia.

Cleópatra é representada desde a Antiguidade com estereótipos de poder, como podemos observar em Vidas Paralelas, de Plutarco. Essa obra, segundo Gregory Balthazar, apresenta "uma profunda mudança de tom em relação à rainha, que passou de uma arquiteta política sem sentimentos para uma mulher que sofreu frente à morte de Antônio, e à ameaça aos filhos e à filha" (Balthazar, 2013, p.164). Para esse autor (p.165), "Plutarco passou bruscamente de uma posição crítica para uma atitude de enobrecimento da figura da última monarca egípcia” (p.165).

Esse imaginário atravessa a Idade Moderna ao longo da peça Antônio e Cleópatra, de William Shakespeare (1623), que a descreve taxativamente como bela mulher detentora de amores, prazeres e poder. Além disso, ela é representada 
em "O Canto do Escravo" de Machado de Assis (1864) como mulher sedutora, e no filme Cleópatra (1963) como portadora de poder mesmo dentro de Roma, quando é retratada adentrando triunfalmente o fórum romano.

Essas questões e representações são mais discutidas hoje do que nunca, lembrando-nos que a separação entre o que é passado e o que é presente nessa reconfiguração histórico-temporal não encontra limites claros. Para exemplificar essa relação aos alunos, o próximo encontro mostraria, por meio da Arqueologia, os resquícios da arquitetura egípcia na atualidade e na sua própria cidade, Pelotas, contribuindo para a reflexão de que o passado afeta constantemente o nosso presente.

No encontro seguinte, discutiu-se o tema "Arqueologia", orientado pela bacharela em Arqueologia Dayanne Dockhorn Seger, e projetou-se o episódio "Regressão Completa" (13 da 2a temporada) da série de televisão Caçadora de Relíquias (Relic Hunter, 1999). Discutiram-se as atividades desenvolvidas pela Arqueologia enquanto disciplina científica, e a diferença entre esse trabalho e os famosos "caçadores de tesouro", personagens aos quais os jovens já estavam habituados em filmes e desenhos animados.

No episódio, acompanhamos a busca por um colar de ouro que supostamente teria pertencido a Cleópatra, concedendo valor ao objeto por seu material e pela importância de sua primeira proprietária. No fim, o colar é incorporado à coleção de um museu no Egito pela protagonista, professora de História especialista na busca de objetos arqueológicos perdidos ou roubados. O contraponto entre o verdadeiro papel do historiador e do arqueólogo e o papel da caçadora de relíquias foi o principal tema debatido durante o encontro. A essa discussão vieram somar-se a definição de Arqueologia, o papel dos objetos como documentos e a necessidade de preservação dos vestígios arqueológicos, entendidos para além das peças consideradas "tesouros".

Para estabelecer a conexão entre o Egito visto no episódio - demonstrado quase exclusivamente por um cenário árido, repleto de pirâmides e construções monumentais - e o Egito real e atual, trouxemos detalhes sobre os sítios arqueológicos reproduzidos nas cenas e imagens dessas mesmas construções retiradas de seu contexto original. Réplicas ou reproduções da arquitetura egípcia são encontradas até mesmo em Pelotas, o que tornou possível levantar questões sobre o significado da cultura egípcia para nós, no presente, e suas influências em nossa sociedade. 
A série e o episódio escolhidos foram ponto de partida eficiente para suscitar a discussão e a curiosidade acerca da disciplina, visto que retratam a Arqueologia como atividade repleta de mistério e aventura. Esse caráter fantasioso concedido à disciplina é bastante criticado na academia, mas, como apontam alguns autores (Carvalho; Silva, 2013; Marwick, 2010; McGeough, 2006; Rosenstone, 1995; Van Dyke, 2006; Zapatero; Castaño, 2008), ele é extremamente eficaz para despertar o interesse pelo passado.

Pouco lembrada nas aulas do ensino básico, a Arqueologia é quase unicamente experimentada pelo público por meio de suas representações nos meios cinematográficos. Séries, filmes, jogos e até mesmo desenhos animados se aventuram a trazer a Arqueologia, imaginada por um viés aventureiro, para mais perto do público. Nesse sentido, esses meios se tornam ferramentas pedagógicas com as quais podemos acessar o público leigo e despertar seu interesse, utilizando suas representações de forma crítica, evidenciado as diferenças e os contrastes entre o que é apresentado e a realidade do fazer arqueológico.

A trama que guia o episódio - o colar de Cleópatra perdido, recuperado pela protagonista após algumas aventuras e uma viagem ao Egito - consegue explicitar perfeitamente a imagem da disciplina e dos profissionais da Arqueologia que os pesquisadores tentam, com afinco, desfazer. O próprio nome da série, Caçadora de Relíquias, pode provocar incômodo no meio acadêmico. No entanto, vale ressaltar que a prática colecionista - a apropriação de itens valiosos de outras culturas para o exibicionismo da elite - que parece inspirar as aventuras dos arqueólogos fictícios de fato existiu nos séculos passados, sendo a própria origem da disciplina, não uma criação original do cinema (Carvalho; Silva, 2013). Se a ficção baseada na Arqueologia e nos seus profissionais perturba tanto os pesquisadores hoje, é porque nosso enfoque, ao longo dos séculos de amadurecimento da disciplina, mudou drasticamente. Hoje buscamos, por meio da Arqueologia, mais do que recuperar artefatos valiosos pertencentes à elite da sociedade, conhecer o cotidiano e os modos de pensar, significar e fazer das sociedades antigas.

Vale lembrar esses aspectos na hora de assistir a tais produções, procurando utilizá-las de forma crítica e como instrumentos para entender a visão leiga acerca da disciplina, bem como para compreender por que as narrativas são construídas desse modo e como podemos propor uma nova visão. Afinal, que conhecimento tem o público a respeito da Arqueologia praticada hoje nas 
universidades? Como o público conhece ou se interessa pelas civilizações antigas fora do ambiente escolar?

O cinema, nesse encontro, confirmou-se como instrumento de diálogo. Os jovens apontaram que a prática do ensino por meio dos filmes é mais satisfatória do que uma aula formal. Percebemos, nos relatos, que apenas a contemplação dos textos dos livros didáticos não proporciona nenhum aprendizado, é necessário haver um discurso mediador e crítico do professor.

Encerramos o ciclo com o tema "Cinema", orientado pelo discente em Cinema de Animação Gabriel Pimenta, projetando o longa-metragem Deuses do Egito (Alex Proyas, 2016) (Figura 2). A discussão voltou-se para a produção cinematográfica, as etapas de constituição de uma obra fílmica e como ela pode ser utilizada como ferramenta de compreensão de temas do passado. Após o filme e a atividade, os alunos questionaram se haveria a possibilidade de criar um filme "verdadeiro" com o auxílio dos pesquisadores. Essa pergunta desencadeou outro tema de discussão: as construções e reconstruções do passado. Explicamos que não é possível reconstruir verdadeiramente o passado, pois existem limitações ao trabalho do arqueólogo e do historiador.

Os bons resultados das sessões com a Companhia de Dança levaram à criação de uma Oficina de Cinema com o discente Gabriel Pimenta durante os meses seguintes e a continuação do Pipoquinha Clássica, desta vez atuando dentro de uma escola municipal.

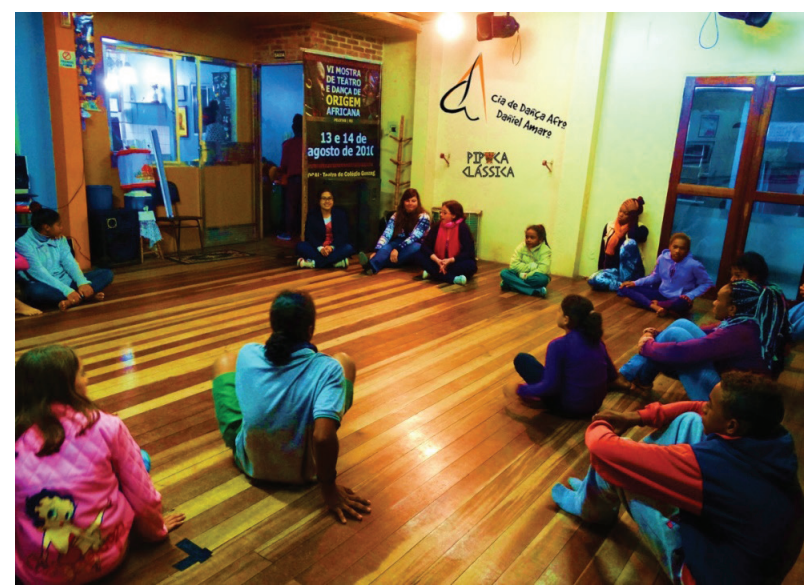

Figura 2 - Jovens da Companhia de Dança Daniel Amaro e equipe do Leca durante a Roda de Conversas que definiu as atividades e as sessões. Fonte: Acervo Leca-UFPel. ${ }^{5}$ 


\section{CONSIDERAÇÕES FINAIS}

Durante as sessões do Pipoca e do Pipoquinha Clássica, desde o início do projeto de extensão, nosso intuito foi promover temas da Antiguidade para o público não especializado de forma dinâmica e interativa. Com a exibição dos filmes, criamos um espaço para discussão dos diversos temas propostos. As sessões do Pipoca Clássica realizadas dentro da universidade contaram com debates multidisciplinares e com a participação de estudantes de diversas áreas do conhecimento, o que gerou novas parcerias, projetos e pesquisas.

Com o Pipoquinha Clássica conseguimos acessar o público infanto-juvenil, que não dispunha de nenhum contato com a universidade ou com os temas tratados fora do ambiente escolar. Para despertar a atenção das crianças e dos jovens, optamos por escutar seus interesses antes de propor uma programação fixa, e exibir animações ou séries de televisão, que geralmente são mais breves do que os longas-metragens, para suscitar a curiosidade sobre as sociedades antigas e sobre o fazer arqueológico e histórico. Esse exercício de reflexão proporcionou novas maneiras de pensar o passado no presente não somente ao público, mas também a nós, pesquisadores.

Trazer nosso tema de estudo e nosso fazer científico, tão especializado e muitas vezes tão introspectivo, a um público como o infanto-juvenil - que requer linguagem diferenciada e abordagem mais dinâmica e sistemática - foi, sem dúvida, um desafio para todos os envolvidos. Essas experiências se mostraram sobretudo enriquecedoras e inspiradoras, e nos motivaram a expandir o projeto no futuro para outros públicos, como o da terceira idade.

\section{REFERENNCIAS}

BAKOS, Margaret Marchiori. O Egito antigo na fronteira entre a ciência e a imaginação. In: FRONTEIRAS E ETNICIDADE NO MUNDO ANTIGO. Congresso da Sociedade Brasileira de Estudos Clássicos, 5., 2005, Pelotas. Anais... Pelotas: Ed. e Gráfica Universitária, 2005. p.1-10. Disponível em: http://www.pucrs.br/ffch/historia/egiptomania/publicacoes/egito2.pdf; Acesso em: 26 jun. 2017.

BALTHAZAR, Gregory da Silva. A(s) Cleópatra(s) de Plutarco: as múltiplas faces da última monarca do Antigo Egito nas vidas paralelas. Dissertação (Mestrado em História) - Programa de Pós-Graduação em História, Setor de Ciência Humanas, Letras e Artes, Universidade Federal do Paraná (UFPR). Curitiba, 2013. Disponível em: http://www.humanas.ufpr.br/portal/historiapos/files/2013/05/Gregory.pdf; Acesso em: 26 jun. 2017. 
BRASIL. Lei no 9.394, de 20 de dezembro de 1996. Disponível em: http://www.planalto.gov.br/ccivil_03/leis/L9394.htm; Acesso em: 26 jun. 2017.

BRASIL. Secretaria de Educação Fundamental. Parâmetros Curriculares Nacionais: história, geografia. Brasília: MEC/SEF, 1997.

CARLAN, Claudio; FUNARI, Pedro Paulo; FUNARI, Raquel. Cinema e o Mundo Antigo: Antiguidade através da sétima arte. Saarbrücken: Novas Edições Acadêmicas, 2015.

CARVALHO, Aline; SILVA, Bruno S. R. da. Arqueologia e socialização do conhecimento: Indiana Jones, mostre-nos o que sabes. Ciência e Cultura, Campinas: SBPC, v.65, n.2, p.45-58, 2013. Disponível em: http://cienciaecultura.bvs.br/scielo. php?pid=S0009-67252013000200017\&script=sci_arttext; Acesso em: 26 jun. 2017.

DIAS, Camila Delmondes et al. Divulgando a arqueologia: comunicando o conhecimento para a sociedade. Ciência e Cultura, Campinas: SBPC, v.65, n.2, p.48-52, 2013. Disponível em: http://cienciaecultura.bvs.br/scielo.php?pid=S0009-67252013000200018\&script=sci_arttext; Acesso em: 26 jun. 2017.

FERRO, Marc. Cinema e História. Trad. Flávia Nascimento. Rio de Janeiro: Paz e Terra, 1992.

HOLTORF, Cornelius. Archaeology is a brand: The meaning of Archaeology in Contemporary Popular Culture. Oxford: Routledge, 2007.

MARWICK, Ben. Self-image, the long view and archaeological engagement with film: an animated case study. World Archaeology, v.42, n.3, p.394-404, 2010. Disponível em: http://faculty.washington.edu/bmarwick/PDFs/Marwick_2010_WA_Wall-E. pdf; Acesso em: 26 jun. 2017.

MCGEOUGH, Kevin. Heroes, Mummies, and Treasure: Near Eastern Archaeology in the Movies. Near Eastern Archaeology, Boston: Asor, v.69, n.3-4, p.174-185, 2006. Disponível em: http://scholar.ulethbridge.ca/sites/default/files/mcgekm/files/nea_ mcgeough_mummies.pdf; Acesso em: 26 jun. 2017.

ROSENSTONE, Robert. The Historical Film as Real History. Film-Historia, Barcelona: Cinema Research and Consulting, v.V, n.1. p.5-23, 1995. Disponível em: http://www.culturahistorica.es/rosenstone/historical_film.pdf; Acesso em: 26 jun. 2017.

SALES, José das Candeias. Cinema e História Antiga: a propósito do filme Cleópatra (1963) de Joseph Leo Mankiewichz. I parte. Cadmo, Lisboa: Centro de História da Universidade de Lisboa, n.19, p.131-154, 2010. Disponível em: https://digitalis-dsp.uc.pt/bitstream/10316.2/23781/1/Cadmo19_Artigo5.pdf?ln=pt-pt; Acesso em: 26 jun. 2017.

SILVA, Semíramis Corsi; FIGUEIREDO, Daniel de. História e Cinema em Sala de Aula: reflexões a partir do filme Alexandria, de Alejandro Amenábar. Chrônidas, Goiânia: UFG, ano V, n.14, p.110-134, 2012. Disponível em: http://www.academia.edu/7806263/ 
Hist\%C3\%B3ria_e_Cinema_em_sala_de_aula_reflex\%C3\%B5es_a_partir_do_filme_ Alexandria_de_Alejandro_Amen\%C3\%A1bar; Acesso em: 26 jun. 2017.

SILVA, Thais Rocha da. O sorriso da esfinge: reflexões sobre o ensino do Egito antigo no Brasil. In: LEMOS, Rennan. O Egito Antigo: novas contribuições brasileiras. Rio de Janeiro: Multifoco, 2014. p.279-300.

TORINO, Isabel Halfen da Costa. Mercúrio na torre do mercado: percurso e significado de um símbolo grego na memória e no patrimônio cultural de Pelotas, RS. Dissertação (Mestrado em Memória Social e Patrimônio Cultural) - Instituto de Ciências Humanas, Universidade Federal de Pelotas (UFPel). Pelotas, 2015. Disponível em: http://wp.ufpel.edu.br/ppgmp/files/2016/11/Isabel-Halfen-daCosta-Torino.pdf; Acesso em: 28 maio 2017.

VAN DYKE, Ruth. Seeing the Past: Visual Media in Archaeology. American Anthropologist, Arlington: American Anthropological Association, v.108, p.370-384, 2006.

ZAPATERO, Gonzalo Ruiz; CASTAÑO, Ana Maria Mansilla. Arqueologia e Cinema: uma história em comum. Revista Arqueologia Pública, Campinas: Unicamp, n.3, p.19-31, 2008.

\section{NOTAS}

${ }^{1}$ Diferentemente da História, a Arqueologia - ciência próxima e com a qual dialogamos neste trabalho - deu um passo em relação ao diálogo e à divulgação científica nos últimos anos. Com a presença da arqueologia preventiva nos processos de licenciamento ambiental desde 2002 (DIAS et al., 2013), instituiu-se a obrigatoriedade de retorno à sociedade dos dados obtidos nas pesquisas, disseminando-os mediante ações educativas e processos museológicos nas comunidades afetadas.

${ }^{2}$ O Leca é coordenado pelos professores Carolina Kesser Barcellos Dias (PPGH/UFPel), Camila Diogo Souza (MAE/USP) e Fábio Vergara Cerqueira (UFPel). Desde 2011, o Leca atua como espaço acadêmico para pesquisa e análise da cerâmica antiga e de diversos outros temas relacionados à Antiguidade na Universidade Federal de Pelotas (UFPel). Os vários projetos e eventos promovidos pelo laboratório suscitam a difusão da História Antiga e da Arqueologia Clássica entre pesquisadores e estudantes brasileiros. Disponível em: http://leca.ufpel.edu.br/; Acesso em: 26 jun. 2017.

${ }^{3}$ Desde 2015, o Pipoca Clássica é coordenado pela profa Carolina Kesser Barcellos Dias e pela prof ${ }^{\mathrm{a}} \mathrm{dr}^{\mathrm{a}}$ Larissa Patron Chaves (Centro de Artes/PPGH - UFPel).

${ }^{4}$ Hércules, 1998, Walt Disney Television Animation.

${ }^{5}$ Atestamos que foi concedida a autorização de direitos de imagem pelos responsáveis dos alunos da Cia. de Dança Afro Daniel Amaro.

Artigo recebido em 5 de maio de 2017. Aprovado em 3 de julho de 2017. 